\title{
A MODEL FOR THE MEASUREMENT OF ECONOMIC FREEDOM
}

\author{
Ángel Díaz and José Luis Montes \\ Universidad Rey Juan Carlos \\ Departamento de Economía Aplicada I \\ Paseo de los Artilleros sn., 28032, Madrid., Spain \\ E-mail: angel.diaz@urjc.es; joseluis.montes@urjc.es
}

\author{
KEYWORDS \\ Model, Structural Equations Modelling, SEM, Index \\ construction, Economic freedom.
}

\begin{abstract}
The paper presents, by means of a structural equations model, an account of the economic freedom factors and their importance. Considering that economic freedom manifests through: business freedom, trade freedom, fiscal freedom, government size, monetary freedom, investment freedom, financial freedom, property rights, freedom from corruption and labour freedom. Results show that all the considered freedoms have statistical significance, being the most influential the ones related to the property rights and the freedom from corruption. Besides, an objective economic freedom index is developed through a new, structural equations based, methodology.
\end{abstract}

\section{INTRODUCTION}

Although the current world liberalization process is one of the most important economic trends in the current years, there are a lack of econometrics models helping to measure and understand its effects and the structure and importance of its underlying economic and social factors. Such a model will enhance the comprehension of the phenomena and assist to their management.

This paper aims to contribute to attenuate these lacks, by developing -applying structural equations modellingan index to measure the economic freedom of a country, or of a significant economical area. Finding out what variables, and to what extent, influence the liberalization process; in order to establish the most efficient economics measures, necessary to reach the required liberalization degree. The definition of economic freedom, considered in this paper, is an absence of government coercion or constraint. The obtained statistical results imply not desirability at all, and are not meant to have any ideological implications.

The paper proceeds as follows, in the first part we outline the method, in the second we propose and estimate the model, in the third we show the results, concluding, in the fourth, with some conclusions and further research suggestions.

\section{METHOD}

There are in the economic literature some high-quality indexes trying to measure the economic freedom. The ones we know are built as a weighted mean of a set of variables. Two main problems arise at this point: The first one is what variables should form part of the index; an economics problem that we are not going to address here. The second is to assign weights to the index components, so that the weight reflects the real importance of the variable. In this paper we propose a solution for this second problem: regard the economic freedom as a latent variable and let the data assign weights to the variables.

In order to construct the index, a system of structural equations, whose outline is presented next, with latent (not measurable directly) variables has been developed. Besides, and as a distinct desirable characteristic in the model, the measurement errors are explicitly included for each variable in the estimation process. The system parameters were estimated by the Full Information Maximum Likelihood (FIML) method and checked by Bayes' estimation, obtaining similar values. To estimate the index weights we considered the database of the Heritage Foundation (heritage.org), covering 162 countries, but the proposed method is equally applicable for any other set of variables.

\section{The Structural Equation System General Model}

The Structural System General model is a mathematical model, a set of linear equations, which encompass a large class of models (Jöreskorg, K.G., 1984). Variables in the equation's system may be either directly observed or unmeasured latent (theoretical), representing concepts not directly observed, that can only be approached and measured trough observed and measurable variables. Latent variables must be continuous, nevertheless observed dependent variables can be continuous, censored, binary, ordered, categorical (ordinal), counts or combinations of these variable types.

Structural equation models are composed of two sub models: the structural model linking only latent variables, and the measurement model, that links each 
latent variable with its correspondent measurement variables (indicators). A causal structure among latent variables is assumed.

Structural equation modelling has certain desirable features: a) explicit inclusion of error's measurement terms for each variable, b) simultaneous estimation of parameters of a series of dependence relationships, where a variable can act as dependent in some equations and independent in other ones, c) can take account of reciprocal causation and recursive and non recursive models, d) can be considered as confirmatory technique and, also, as exploratory.

\section{The Model}

The Structural System General Model is defined (Jöreskorg, K.G., op. cit.) through a system of linear structural relations, whose matrix representation is:

$$
\eta=\alpha+\mathrm{B} \eta+\Gamma \xi+\zeta
$$

where $\eta(\mathrm{mx} 1)$ and $\xi$ (n x 1) are random vectors of, respectively, latent dependent and independent variables, $\alpha$ is a ( $\mathrm{m} \mathrm{x} 1)$ intercept's terms vector, $\mathrm{B}(\mathrm{m}$ $\mathrm{x} m)$ is the coefficient's matrix for the latent endogenous variables, representing the effects of $\eta$ variables on other $\eta$-variables, $\Gamma(\mathrm{m} \times \mathrm{n})$ is the coefficient matrix for latent exogenous variables representing the direct effects of $\xi$-variables on $\eta$ variables and $\zeta$ is a $(\mathrm{m} \times 1)$ vector indicative of the random disturbance in the equation. It is assumed that $E(\eta)=0, E(\xi)=0, E(\zeta)=0$.

Observed (measured) variables are represented by the vectors $y(\mathrm{p} \times 1)$, where $\mathrm{p}$ is the number of indicators of $\xi$, and $x(\mathrm{q} \times 1)$, where $\mathrm{q}$ is the number of indicators of $\eta$, which are related to de latent variables trough the equations:

$$
\begin{aligned}
& y=\tau_{y}+\Lambda_{y} \eta+\varepsilon \\
& x=\tau_{x}+\Lambda_{x} \xi+\delta,
\end{aligned}
$$

where $\mathcal{E} \quad(\mathrm{p} \times 1)$ and $\delta$ (q $\times 1)$ are error terms vectors. It is assumed that $\mathcal{E}$ is uncorrelated with $\eta, \xi$ and $\delta$; and that $\delta$ is uncorrelated with $\eta, \xi$ and $\varepsilon$. $\Lambda_{y}(\mathrm{p} \times \mathrm{m})$ and $\Lambda_{x}(\mathrm{q} \times \mathrm{n})$ are matrices containing the structural coefficients $\lambda_{i j}$ linking the latent and measured (observed) variables, and $\tau_{y}(\mathrm{p} \times 1)$ and $\tau_{x}$ (q $x$ 1) are vectors of constant intercept terms.
The structural equation model fundamental hypothesis is: $\sum=\sum(\theta)$, where $\sum$ is the population covariance matrix and $\sum(\theta)$ is the model's covariance matrix, written as a function of a vector of the model parameters $\theta$. Parameter estimates are obtained by minimizing some fit function $F(\theta)=F(S, \hat{\Sigma}(\theta))$.

Once estimated the parameters, the model covariance matrix is compared with the empirical data covariance matrix, and if the difference between both matrixes is statistically acceptable the proposed structural equation model is acknowledged as a plausible explanation of the reality.

The measurable variables, below, that have been considered are defined following Holmes et al. (2008), and their original measurements scales has been transformed to the range $0-100$, to ease the comparisons, meaning 0 minimum degree and 100 maximum. A score of 100 signifies an economic environment or policies most favourable for economic freedom.

Business freedom: ability to create, operate, and close an enterprise quickly and easily.

Trade freedom: is a composite measure of the absence of tariff and non tariff barriers that affect imports and exports of goods and services.

Fiscal freedom: is a measure of the burden of government from the revenue side. It includes both the tax burden in terms of the top tax rate on income (individual and corporate separately) and the overall amount of tax revenue as a portion of gross domestic product (GDP).

Government size: is defined to include all government expenditures, including consumption and transfers. Ideally, the state will provide only true publics goods, with an absolute minimum of expenditure.

Monetary freedom: combines a measure of price stability with an assessment of price of controls. Both inflation and price controls distort market activity. Price stability without microeconomic intervention is the ideal state for the free market.

Investment freedom is an assessment of the free flow of capital, especially foreign capital

Financial freedom: is a measure of banking security as well as independence from government control. State ownership of banks and other financial institutions such as insurer and capital markets is an inefficient burden and political favouritism has no place in a free capital market 
Property rights: is an assessment of the ability of individuals to accumulate private property, secured by clear laws that are fully enforced by the state.

Freedom from corruption: is based on quantitative data that asses the perception of corruption in the business environment, including levels of governmental legal, judicial, and administrative corruption.

Labor freedom: is a composite measure of the ability of workers and businesses to interact without restriction by the state.

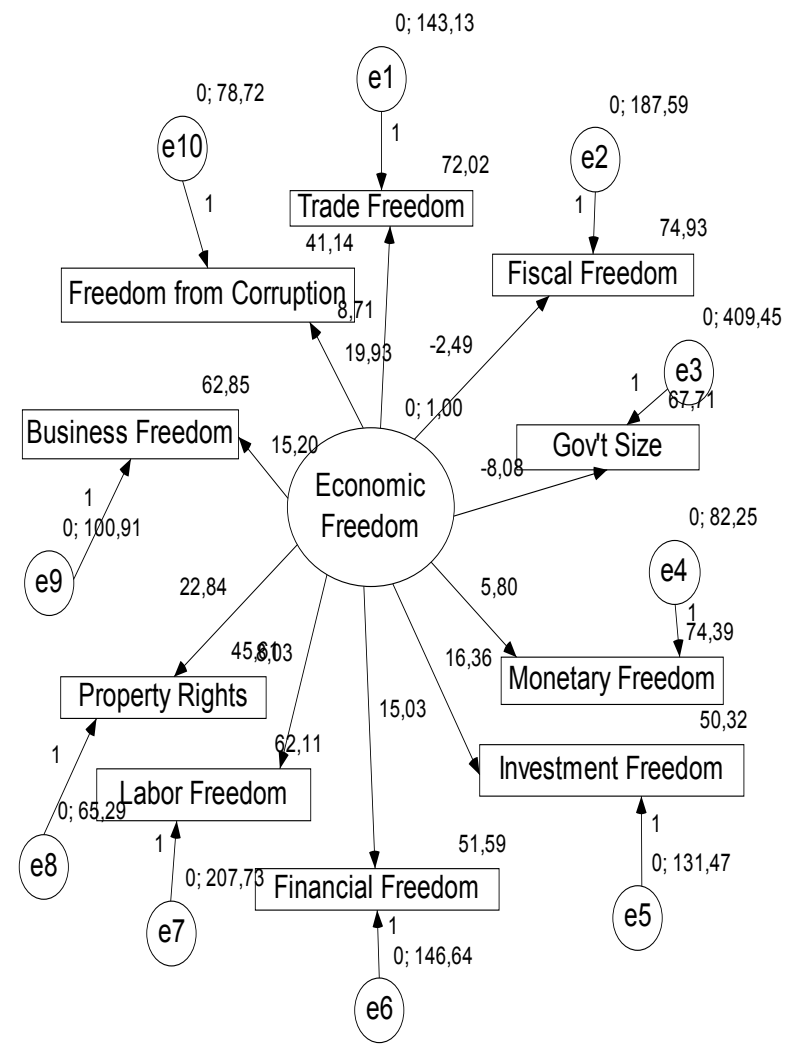

Figure 1: Model Outline

\section{RESULTS}

Results are shown in figure 1 and in table 1 . Figure 1 shows the model estimates' outline. We can observe three types of variables: non-observed latent variables (Economic Freedom), indicators (Table 1), and measurement errors (e). The structural equation 3 relates the matrix of exogenous latent variables $\xi$ with their indicators $(\mathrm{x})$; in this case with the economic freedom and the matrix of the measurement errors. The equation 2 shows the relationships among indicators of the endogenous latent variable $(\eta)$, being " $y$ " the matrix of these indicators, $\eta$ the latent endogenous variables matrix, and $\mathcal{E}$ the estimation error. Finally, the equation 1 shows the relationships among non-observed latent variables that do not exist in this case, but it is also included for the sake of model completeness.

All variables (table 1) are statistically significant (pvalue $<0.001)$, except the Fiscal freedom $(\mathrm{p}=0.028)$. Most of the parameters values are positive with the unexpected exception of Fiscal Freedom and Government size.

The variables with higher importance (with higher weights) are Property Rights and Freedom from Corruption. Statistically, these two variables are the ones that better explain the Index of Economic Freedom variability. From an economic point of view, those countries making more efforts trying to reduce corruption and protect property rights will achieve more economic freedom. This fact is especially important in less developed countries where, as expected, these factors are the first to improve when trying to assure a minimum of economic freedom.

Next to the previous ones more influent variables are those related with finance. Once assured the property rights and the freedom from corruption, the most important variables in the index are Investment Freedom, Financial Freedom and Business Freedom. Countries with fewer barriers of this type will have more economic freedom.

The third group of variables, although with less importance, than the preceding are Freedom of Trade, Freedom of Work and Monetary Freedom.

To conclude, two variables have negative signs: Government Size and Fiscal Freedom. This result is quite surprising and requires further research.

Table 1: Maximum Likelihood Estimates. Regression Weights

\begin{tabular}{|cc|ccc|}
\hline Indicators & & Estimate & S.E. & $\mathrm{P}$ \\
\hline FiscalFreedom & $<---$ Ec.Fr. & $-2,491$ & 1,132 &, 028 \\
InvestmentFreedom & $<---$ Ec.Fr. & 16,364 & 1,323 & $* * *$ \\
FinancialFreedom & $<---$ Ec.Fr. & 15,033 & 1,311 & $* * *$ \\
BusinessFreedom & $<---$ Ec.Fr. & 15,204 & 1,195 & $* * *$ \\
TradeFreedom & $<---$ Ec.Fr. & 8,710 & 1,099 & $* * *$ \\
LaborFreedom & $<---$ Ec.Fr. & 8,030 & 1,267 & $* * *$ \\
PropertyRights & $<---$ Ec.Fr. & 22,842 & 1,463 & $* * *$ \\
GovtSize & $<---$ Ec.Fr. & $-8,082$ & 1,722 & $* * *$ \\
FreedomfromCorrup. $<---E c . F r$. & 19,931 & 1,349 & $* * *$ \\
MonetaryFreedom & $<---$ Ec.Fr. & 5,802 &, 814 & $* * *$ \\
\hline
\end{tabular}


Table 2: Standardized Regression Weights

\begin{tabular}{|c|c|c|}
\hline Indicators & & Estimate \\
\hline FiscalFreedom & $<---$ Ec.Fr. &,- 179 \\
\hline InvestmentFreedom & $<---$ Ec.Fr. &, 819 \\
\hline FinancialFreedom & $<---\quad$ Ec.Fr. &, 779 \\
\hline BusinessFreedom & $<---$ Ec.Fr. &, 834 \\
\hline TradeFreedom & $<---$ Ec.Fr. & ,589 \\
\hline LaborFreedom & $<---$ Ec.Fr. & ,487 \\
\hline PropertyRights & $<---$ Ec.Fr. & ,943 \\
\hline GovtSize & $<---$ Ec.Fr. &,- 371 \\
\hline FreedomfromCorruption & $<--$ Ec.Fr. & ,914 \\
\hline MonetaryFreedom & $<---$ Ec.Fr. &, 539 \\
\hline
\end{tabular}

Table 3: Intercepts

\begin{tabular}{|lccc|}
\hline Indicators & Estimate & S.E. & P \\
\hline BusinessFreedom & 62,847 & 1,459 & $* * *$ \\
GovtSize & 67,715 & 1,745 & $* * *$ \\
TradeFreedom & 72,016 & 1,185 & $* * *$ \\
FreedomfromCorruption & 41,140 & 1,747 & $* * *$ \\
FiscalFreedom & 74,928 & 1,115 & $* * *$ \\
FinancialFreedom & 51,592 & 1,546 & $* * *$ \\
LaborFreedom & 62,113 & 1,321 & $* * *$ \\
InvestmentFreedom & 50,318 & 1,600 & $* * *$ \\
PropertyRights & 45,605 & 1,940 & $* * *$ \\
MonetaryFreedom & 74,390 &, 862 & $* * *$ \\
\hline
\end{tabular}

\section{CONCLUSIONS}

In this paper we have proposed, through a structural equations model, an explanation of the economic freedom factors and their importance.

All the considered freedoms have statistical significance, with p-values lower than 0.001 (except fiscal freedom $\mathrm{p}=0.028$ ).

The most influential freedoms are the ones related to the property rights and the freedom from corruption, showing that a sense of safety is of the utmost importance for the economic freedom.

As expected, there is a negative correlation between the economic freedom and the fiscal freedom and between the economic freedom and the government size.

Another contribution of this paper is the development of an economic freedom index. As said above, in spite of the number of economic freedom' indexes in economic literature, the variables weight assignments is somehow subjective and in some cases even lacks of a scientific basis what hinders a rigorous analysis.

\section{REFERENCES}

Bentler, P.M. and D.G. Bonett. 1980. "Significance tests and goodness of fit in the analysis of covariance structures". Psychological Bulletin, 88, 588-606.

Bentler, P.M. 1990. "Comparative fit indexes in structural models". PsychologicalBulletin, 107, 238-246.

Bollen, K.A. 1986. "Sample size and Bentler and Bonett's nonnormed fit index". Psychometrika, 51, 375-377.

Bollen, K.A. 1989. "A new incremental fit index for general structural equation models". Sociological Methods and Research, 17, 303-316.

Bollen, K. A, and P. J. Curran. 2006. Latent Curve Models. A Structural Equation Perspective. Wiley.

Díaz, A. and J. L. Montes. 2005. "La competitividad de las regiones europeas: Una propuesta metodológica para evaluar el efecto de las tecnologías digitales". XXXI Reunión de Estudios Regionales: "El estado autonómico a debate: eficiencia, eficacia $\mathrm{y}$ solidaridad". Alcalá de Henares. (Nov).

Díaz, A. and J.L. Montes. 2006. "Digital Technologies and Competitiveness. Effects on Manufacturing Companies: The Spanish Case". In From Small Firms to Multinationals: Industrial, Entrepreneurial, Managerial, Financial, Fiscal, Transaction Cost and Consumer Perspectives in era of Globalisation. 231-244. Ioannis-Dionysios Salavrakos (Eds.). Athens.

Díaz, A., J. M. Menéndez, and J.L. Montes. 2006. "Los recursos humanos en la empresa industrial: un análisis empírico sobre la eficiencia del capital humano". Revista de Trabajo y Seguridad Social, 274. Centro de Estudios Financieros.

Holmes, King R., Edwin J. Feulner and Mary Anastasia 0'Grady. 2008. The 2008 Economic Freedom Index. The Heritage Foundation and the Wall Street Journal.

Jöreskog, K.G. and D.Sörbom. 1984. LISREL-VI user's guide. Mooresville, IN. USA. Scientific Software.

ANGEL DÍAZ, Master in Applied Economics Analysis from the Universidad Autónoma de Barcelona (UAB) and B.A. in Economics and in Business Administration from Carlos III University in Madrid. Associate professor in the Economics and Economic History department of the UAB and researcher in the Project Internet Catalonia. He is currently head of the research department of the SEPI Foundation and a member of the Department of Applied Economics I on the Rey Juan Carlos University in Madrid, where he teaches statistics.

JOSÉ-LUIS MONTES. Ingeniero Industrial (Universidad Politécnica de Madrid) and Ph.D. in Economics (Universidad Pontificia Comillas). His research interests are: economic modelling of competitiveness, efficiency and quality. At this time is Professor of Statistics and Mathematics at the Universidad Rey Juan Carlos in Madrid. 